\section{OPEN ACCESS}

Edited by:

Mohd Faris Khamidi,

Qatar University, Qatar

Reviewed by:

Ali Sarrafi Nik,

Islamic Azad University, Central Tehran

Branch, Iran

Danny Li,

City University of Hong Kong, Hong

Kong SAR, China

*Correspondence:

Eduardo Krüger

ekruger@utfpr.edu.br

Specialty section:

This article was submitted to

Sustainable Infrastructure,

a section of the journal

Frontiers in Sustainable Cities

Received: 24 September 2021

Accepted: 17 January 2022

Published: 07 March 2022

Citation:

Krüger E (2022) Seasonal Effects of Daylight Conditions on Occupant

Perception and Skin Temperature. Front. Sustain. Cities 4:782712. doi: 10.3389/frsc.2022.782712

\title{
Seasonal Effects of Daylight Conditions on Occupant Perception and Skin Temperature
}

\section{Eduardo Krüger*}

Departamento de Construção Civil, Universidade Tecnológica Federal do Parana, Campus Curitiba - Sede Ecoville, Curitiba, Brazil

Current research on the relationship between daylight and well-being has shown that access to daylight plays a relevant role both in terms of light perception and with respect to physiological mechanisms not directly related to vision. The aim of this paper is to analyze changes in reported light perception and in physiological responses, represented in this case by the skin temperature of research participants $(n=16)$ across three seasons (winter, spring and summer seasons) in a temperate, mid-latitude location, Karlsruhe, in southern Germany $\left(49^{\circ} \mathrm{N}, 8.5^{\circ} \mathrm{E}\right.$ ). Sessions have been held in thermally stable rooms of a climate chamber, with daylight exposure to two opposing solar orientations of the glazed façade, namely equatorial and non-equatorial orientations, over 5-h morning sessions. Differences in light perception as well as changes in physiology have been observed. Results showed an increased sensitivity of the individuals in terms of light perception to changes in daylight in winter while such sensitivity dropped in spring and summer, with greater daylight availability and diminished lighting variability during sessions. Due to the intrinsic relationship between light perception and circadian entrainment, the same was verified for changes in skin temperature, which were also found to be significantly related to daylight availability. Seasonal influence suggests that variability of brightness and correlated color temperature (CCT) of natural light can affect both psychological and physiological patterns in humans.

Keywords: daylight, solar access, circadian cycle, skin temperature, light perception

\section{INTRODUCTION}

Our circadian rhythm is controlled by the activation of melatonin production with concurrent suppression of cortisol during the night, followed by a reversal of this mechanism during the day, cyclically interchanging latent and active states, commonly known as the sleep/wake cycle, within $\sim 24 \mathrm{~h}$ or so. The adaptation of our species to natural rhythms over time, particularly as regards the mammalian hypothalamus, created a perfect synchronization to the diurnal and nocturnal periods (Kudielka and Kirschbaum, 2003). Such synchronization is also season dependent in connection to the availability of daylight, with a production of melatonin taking place during longer periods in winter than in summer (Mead, 2008).

Modern life, however, interfered in this process greatly. On one hand, ubiquitous access to artificial light sources allows human beings to prolong their active state during nighttime. On the other, in many buildings the reduced access to natural light lead to an increase and even to 
a dependency on artificial lighting of its occupants in order to perform their activities indoors. Under such conditions, the circadian rhythm gets seriously disrupted and consequences are noticed in terms of health and wellbeing. Mood and mental health disorders can be associated to disruptions of the circadian rhythms (Walker et al., 2020) as well as alterations in cognitive abilities with related impacts on health and behavior (Sharma et al., 2016).

The direct relationship between circadian rhythms and daylight further stresses the relevance of providing indoor environment with daylight, aiming at healthy indoor built environments. Aries et al. (2015) performed a literature review on health effects related to daylight exposure and found that this relationship is not always clear and convincingly explained in published papers due to incomplete reporting. As put forth by these authors "There is only limited statistically significant and well-documented scientific proof for the link between daylight and its potential health consequences."

Biological markers can be used for monitoring the circadian rhythm of individuals. Hormone signals as melatonin and cortisol as well as other hormones such as the growth hormone ghrelin (Qian et al., 2019) can gauge the sleep/wake cycle. However, collecting samples of biological material such as blood, urine and saliva, as required for this sort of analysis, can be rather uncomfortable and invasive to research participants. New evidence suggests that other circadian biological markers, such as heart rate variability (Boudreau et al., 2012), blood pressure (Smolensky et al., 2007) and body temperature (Buhr et al., 2010) can also serve as good indicators of circadian rhythms.

Apart from light intensity, given as room illuminance (E, in $\mathrm{lx}$ ), some of the intrinsic characteristics of light that can influence aspects not related to vision in humans are the correlated color temperature (CCT) (Dai et al., 2017), the dominant wavelength (DWI) (Brainard et al., 2001) and the circadian action factor $\left(\mathrm{a}_{\mathrm{cv}}\right)$ (Gall et al., 2004). The latter is defined by the determination of the circadian action function $[c(\lambda)]$ and the circadian radiation quantities (Xec) of a light source, as mathematically demonstrated by Gall et al. (2004).

Research suggests that there is a linkage between CCT, alertness and cognitive performance. From a study with 16 subjects, exposed to different artificial light settings for two consecutive hours during evening sessions, Chellappa et al. (2011) and Stefani et al. (2020) concluded that commercially available compact fluorescent lights with different color temperatures could significantly affect circadian physiology and cognitive performance. As for DWl, studies have shown that suppression of melatonin is more sensitive to light at shorter wavelengths, with the predominance of the blue spectrum as the most effective for the maintenance of circadian functions (Brainard et al., 2001; Thapan et al., 2001). The circadian action factor, in turn, has a positive correlation with CCT meaning that the colder the apparent temperature of the light, the greater its circadian effectiveness is (Gall et al., 2004).

As for light perception, the visual appraisal of the surrounding environment is vital to the circadian timekeeping. Blind people with no perception of light are hardly able to maintain a normal circadian rhythm without the visual input. In a comprehensive study with 127 participants of a controlled longitudinal study on circadian disorders, Flynn-Evans et al. (2014) found out that the majority of the subjects that had no light perception (63\%) had either phased or nonentrained circadian rhythms while participants with light perception had in their majority (69\%) entrained circadian cycles. Authors concluded that the ability of the subjects to process the circadian light signals is severely hindered in the case of blind subjects. Thus, light perception is a necessary condition for circadian regulation. In a study on thermal acclimatization of subjects to the outdoor environment parting from differing light-exposure conditions, Lam et al. (2021) showed correlations between precedent visual conditions and reported thermal sensations, which point to important interactions between different aspects related to human perception of the built environment (Chinazzo et al., 2019; Ko et al., 2020).

Two fundamental and intermingled factors related to the relationship between humans and light are dealt with in this chapter, namely the subjective aspect represented by light perception and the biological marker expressed by skin temperature.

\section{AIM OF THE STUDY}

The purpose of this study is to evaluate seasonal influences on subjective daylight perception and physiological changes in skin temperature of participants exposed to daylight variations in a thermally controlled environment. Secondary objectives are to examine the sensitivity of subjective light perception over different seasons and light exposures (given by the window orientation during each session) and to see how that sensitivity affects a biological marker, in this case skin temperature.

\section{MATERIALS AND METHODS}

The study was carried out in a climate chamber at the Karlsruhe Institute of Technology, located in Karlsruhe, Germany $\left(49^{\circ} \mathrm{N}\right.$, $8.5^{\circ}$ ). Local climate can be defined as warm and temperate, "Cfb" type according to the Köppen-Geiger climate classification (Kottek et al., 2006). The average annual temperature is $10.5^{\circ} \mathrm{C}$, with a daily average in the coldest month (January) of $1.1^{\circ} \mathrm{C}$ and of $19.7^{\circ} \mathrm{C}$ in the hottest month (July) (www.climate-data.org). In terms of daylight availability, the length of day varies considerably between about $8 \mathrm{~h}$ in the winter solstice to $16 \mathrm{~h}$ in the summer solstice (Figure 1A-light blue color corresponds to daylight hours, dark gray color to nighttime and intermediate colors to twilight). Solar radiation data provide a general outlook of daylight potentials in Karlsruhe, with large differences noticed in radiation amount between seasons (Figure 1B).

The climate chamber is composed of two adjacent $24 \mathrm{~m}^{2}$ rooms (Figure 2), painted white (solar reflectance assumed as $80 \%)$ with a light-gray colored floor (50\% reflectance) and white ceiling (reflectance of $80 \%$ ). It was designed as a semicontrollable environment with operable windows. Both rooms have two workstations each, with fast internet connection, 


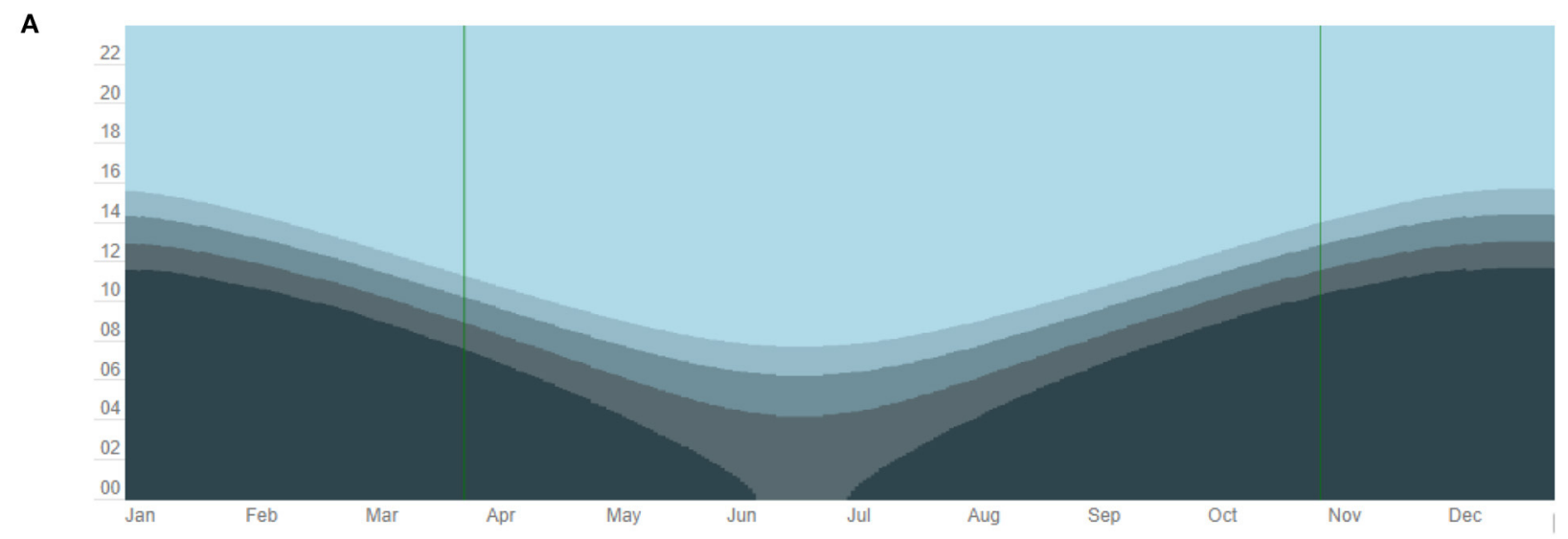

B

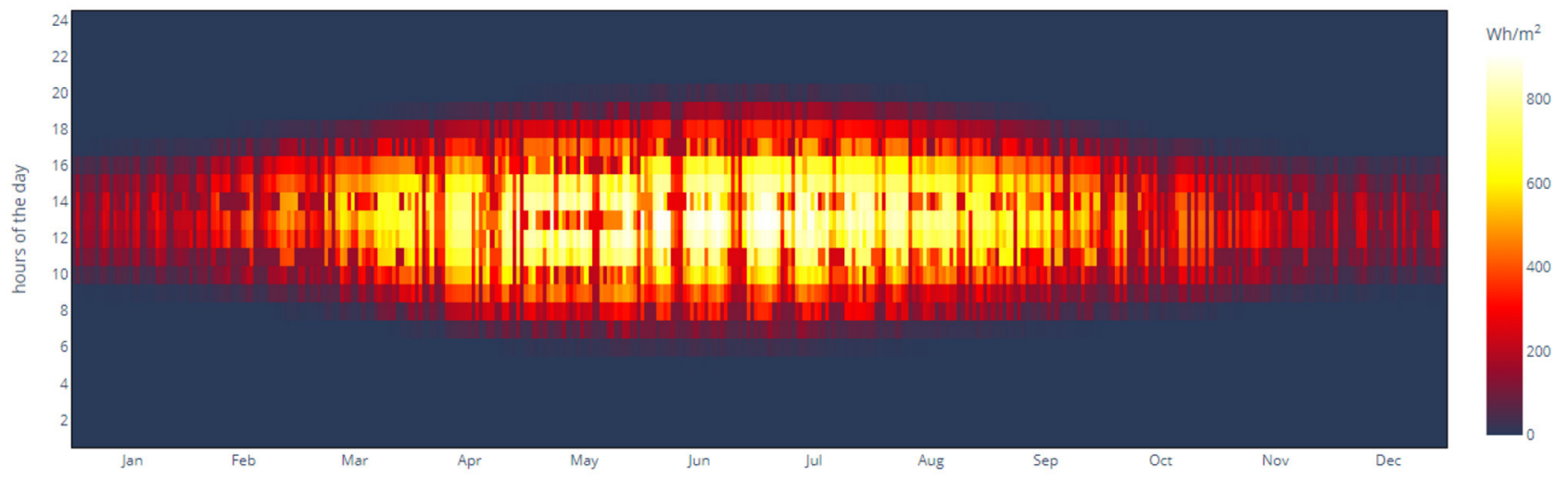

FIGURE 1 | Length of day (A) and false-color map for global solar radiation data (B) for Karlsruhe, Germany Sources: https://www.timeanddate.com/sun/germany/ karlsruhe, Betti et al., 2021-https://clima.cbe.berkeley.edu/.


FIGURE 2 | Floor plan and photograph of the facility in summer (July 2015).

closely resembling office environments. Glazings have triplepaned windows with a VLT (Visible Light Transmittance) of 70 and a window-to-wall ratio of $\sim 75 \%$. The upper fixed window panels have a VLT 72. Thanks to a rotating mechanism at the 
bottom of the facility, the facility and, thus, the glazed façade can take different solar orientations. A thorough description of the facility is presented by Wagner et al. (2018).

The sample consisted of 16 German males with a mean height of $1.80 \mathrm{~m}$ (SD $0.06 \mathrm{~m}$ ), weight of $80 \mathrm{~kg}$ (SD $8.9 \mathrm{~kg}$ ), and 24.9 years old (SD 3.6) who stayed for five consecutive hours inside the chamber, between $8 \mathrm{a} . \mathrm{m}$. and 1 p.m., under controlled thermal conditions. All wore standard clothing (sneakers, t-shirt and jeans, yielding a clothing insulation of 0.7 clo, ISO 9920 ISO 9920., 2007), as per experimental protocol. Metabolic rate was assumed to correspond to a seated position, reading and doing light work $\left(70 \mathrm{~W} / \mathrm{m}^{2}\right.$ or 1.2 Met, ISO 7730 ISO 7730 , 2005). During their stay in the climate chamber, participants were free to do as they please, as long as they would fill out the questionnaire forms submitted to them electronically at designated times following an alarm signal.

Light exposure conditions were tested during 12 field campaigns carried out over three seasons: winter, spring and summer of 2015, with test days lying as close as possible to winter and summer solstices and the vernal equinox. In winter, measurements took place between January 13 and February 5, in spring, between April 3 and April 30, and in

TABLE 1 | Orientation of glazed façade and climatic conditions on test days with Eq and Neq daylight exposures and days with static, electric lighting for winter, spring and summer, with highlighted 3-day campaigns.

\begin{tabular}{|c|c|c|c|c|c|c|c|c|c|c|c|c|}
\hline \multicolumn{13}{|c|}{ Winter } \\
\hline Test day & 1 & 2 & 3 & 4 & 5 & 6 & 7 & 8 & 9 & 10 & 11 & 12 \\
\hline Light source & Eq & Elect & Neq $E$ & Elect & $\mathrm{Neq}$ & $\mathrm{Eq}$ & $\mathrm{Eq}$ & $\mathrm{Neq}$ & Elect & Neq & $\mathrm{Eq}$ & Elect \\
\hline \multicolumn{13}{|c|}{ Spring } \\
\hline Test day & 13 & 14 & 15 & 16 & 17 & 18 & 19 & 20 & 21 & 22 & 23 & 24 \\
\hline Light source & $\mathrm{Eq}$ & Elect & Neq 1 & $\mathrm{Neq}$ & $\mathrm{Eq}$ & Elect & $\mathrm{Eq}$ & $\mathrm{Neq}$ & Elect & Elect & $\mathrm{Neq}$ & $\mathrm{Eq}$ \\
\hline \multicolumn{13}{|c|}{ Summer } \\
\hline Test day & 25 & 26 & 27 & 28 & 29 & 30 & 31 & 32 & 33 & 34 & 35 & 36 \\
\hline Light source & Elect & $\mathrm{Eq}$ & Neq 1 & Neq $E$ & Elect & Eq & Eq & Elect & $\mathrm{Neq}$ & $\mathrm{Neq}$ & Eq & Elect \\
\hline
\end{tabular}

Eq, equatorial; Neq, non-equatorial; Elect, electric light source. summer between June 23 and July 16 thus undergoing strong variations in global solar radiation, light intensity, and daylight duration (cf. Figure 1). Participants were tested in groups of four, two participants per room, undergoing three different light exposures, as shown in Table 1. In this case, during days 1-3, four participants were exposed to three different light exposures in a row, during days $4-6$, another group of participants, and so on successively.

The two daylight situations were for the solar orientation of the glazed façade predominantly to the south ("equatorial orientation") and orientation of glazed façade predominantly to the north ("non-equatorial orientation"). Both façade orientations were defined from daylight simulations (Krüger et al., 2018), which identified opposing orientations that would yield a maximum differentiation in terms of daylight, also accounting for existing obstructions, yet without any glare instances at desk level. For this study, seasonal effects on research participants are tested specifically regarding daylight exposure, thus the sessions with electric light source are not considered in the analysis.

Ahlborn (ALMEMO 2690) loggers were set to record indoor conditions of the air temperature and humidity, globe temperature and air velocity; the mean radiant temperature was calculated according to ISO 7726 (ISO 7726, 2001). Quasi steadystate thermal conditions were ensured within the lower and upper limits of the thermal comfort zone of a "class B" thermal environment, as defined by the PMV index (ISO 7730 ISO $7730,2005)$. Food intake and beverages were controlled during exposure and only still water and neutral, sugarless biscuits and fruits were provided during the 5 -h sessions.

Desk illuminance (E, given in $\mathrm{lx}$ ), correlated color temperature (CCT, given in $\mathrm{K}$ ), dominant wavelength ( $\mathrm{DWl}$, given in $\mathrm{nm}$ ) and the circadian action factor $\left(\mathrm{a}_{\mathrm{cv}}\right.$, non-dimensional) were monitored by two JETI Specbos 1201 spectroradiometers, at each office. The equipment was positioned $\sim 1.5 \mathrm{~m}$ from the glazed façade, at desk level (about $0.90 \mathrm{~m}$ from the floor). Sampling time was set to every $5 \mathrm{~min}$.

Skin surface temperature $\left(\mathrm{T}_{\mathrm{sk}}\right.$, given in $\left.{ }^{\circ} \mathrm{C}\right)$ was measured at four body points according to ISO 9886 (ISO 9886., 2004),

TABLE 2 | Questions and range of answers concerning visual perception.

\begin{tabular}{|c|c|c|c|c|c|c|c|}
\hline \multicolumn{8}{|c|}{ Q.2-How satisfied are you with the room illumination? } \\
\hline Dissatisfied & & & & & & Satisfied & No response \\
\hline \multicolumn{8}{|c|}{ Q.4-What is your opinion about the illumination level at the workplace? } \\
\hline-3 & -2 & -1 & 0 & 1 & 2 & 3 & Null \\
\hline Too dark & & & & & & Too bright & No response \\
\hline Significantly darker & & & & & & Significantly lighter & No response \\
\hline \multicolumn{8}{|c|}{ Q.7-I would like the room illumination level to be: } \\
\hline-3 & -2 & -1 & 0 & 1 & 2 & 3 & Null \\
\hline Significantly darker & & & & & & Significantly lighter & No response \\
\hline
\end{tabular}


TABLE 3 | Summary table for seasons and daylight exposures (9 a.m. to 12:50 p.m.).

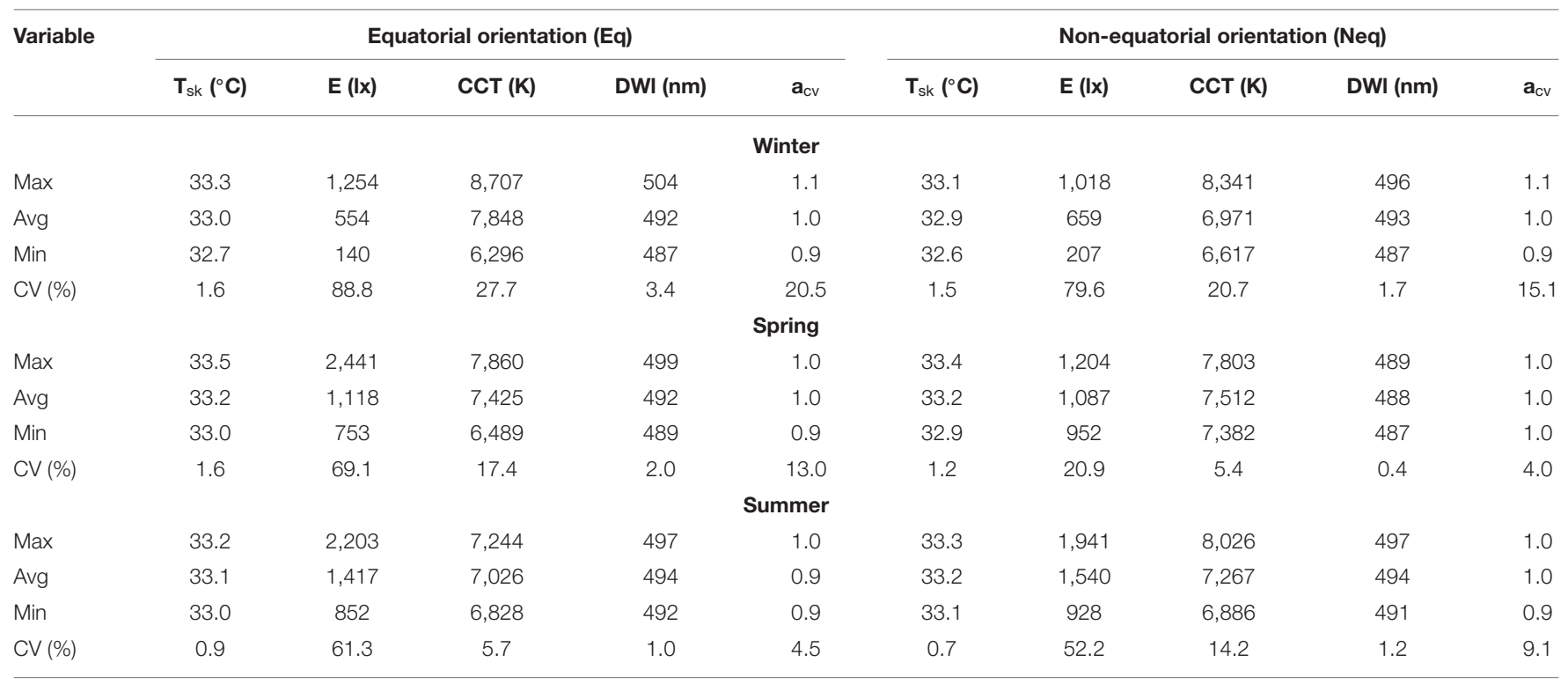

Maximum, average and minimum values obtained and the coefficient of variation for the group-averaged skin temperature ( $T_{\text {sk }}$ ), horizontal desk illuminance (E), correlated color temperature (CCT), dominant wavelength (DWI), and circadian action factor ( $\left.a_{C v}\right)$ (Gall et al., 2004).

TABLE 4 | Spearman rho-correlations (rs) between objective data and subjective responses.

\begin{tabular}{lllcc}
\hline Season & Façade orientation & Variable & $\begin{array}{c}\text { Questionnaire } \\
\text { item }\end{array}$ & $\begin{array}{c}\text { Spearman } \\
\text { correlation } \\
\text { (rs) }\end{array}$ \\
\hline Summer & Non-equatorial & $\mathrm{DWI}(\mathrm{nm})$ & $\mathrm{Q} .7$ & $0.715^{\star \star}$ \\
Summer & Non-equatorial & $\mathrm{a}_{\mathrm{CV}}$ & $\mathrm{Q} .7$ & $-0.715^{\star \star}$ \\
Summer & Equatorial & $\mathrm{E}(\mathrm{l} \mathrm{x})$ & $\mathrm{Q} .2$ & $0.509^{\star \star}$ \\
Winter & Non-equatorial & $\mathrm{CCT}(\mathrm{K})$ & $\mathrm{Q} .7$ & $-0.715^{\star \star}$ \\
Winter & Equatorial & $\mathrm{CCT}(\mathrm{K})$ & $\mathrm{Q} .5$ & $0.624^{\star}$ \\
Winter & Equatorial & $\mathrm{a}_{\mathrm{CV}}$ & $\mathrm{Q} .5$ & $0.624^{\star}$ \\
Winter & Equatorial & $\mathrm{E}(\mathrm{lx})$ & $\mathrm{Q} .5$ & $-0.624^{\star}$ \\
Winter & Equatorial & $\mathrm{DWl}(\mathrm{nm})$ & $\mathrm{Q} .5$ & $-0.624^{\star}$
\end{tabular}

"Ntatistical significance at 0.01 level (two-tailed).

"At 0.05 level (two-tailed).

namely at neck, right scapula, right shin and left hand, applying respective weighting coefficients. Measurements were taken with Thermochron iButton sensors DS1921H-F5.

Although more complete IEQ (Indoor Environmental Quality) questionnaires were responded at given intervals by the respondents, as per experimental protocols, the focus here is on subjective responses regarding light perception in the work environment, cast as 12:30 pm (Table 2). The Questionnaire for Assessment of Light Situations proposed by the LiTG (Deutsche Lichttechnische Gesellschaft -Vandahl et al., 2016) was used in the sessions.

Research protocols have been duly approved by the Ethics Committee of the Karlsruhe Institute of Technology.

Statistical analysis was performed using IBM's SPSS Statistics ${ }^{\circledR} 22$ software.

\section{RESULTS}

Results are presented in two sections, namely subjective daylight judgment and physiological changes observed in skin temperature of participants for seasonal variations of light exposure. Table 3 summarizes measured data for the main light-related variables in the rooms alongside monitored skin temperatures throughout the seasons and daylight exposures, for the time frame 9 a.m. to 12:50 p.m. The first hour was excluded for this table, as the skin temperature went through an acclimation period in some cases up to an hour after participants entered the indoor thermal environment.

The largest variations in all light-related variables are observed in winter, gradually reducing toward summer. The physiological response (skin temperature, $\mathrm{T}_{\text {sk }}$ ) is small but somewhat larger in winter for both daylight exposures. The correlated color temperature for the two daylight configurations roughly corresponds to a cool "bluish". The circadian action factor $\left(\mathrm{a}_{\mathrm{cv}}\right)$ is high for the two daylight exposures and above 0.76, a value usually found for direct solar incidence, according to Gall et al. (2004).

\section{Daylight Perception}

Given the non-parametric nature of the evaluated data, verified with Shapiro-Wilk and Kolmogorov-Smirnov tests, Spearman rank-correlations were employed for comparisons between objective light-exposure data and subjective responses (visual perception) with SPSS. Only significant correlations between pairs of data are shown (Table 4), occurring more frequently in winter.

In winter, when variations in light-related variables are larger during sessions, subjects undergo a wide range of daylightexposure conditions over their 5-h stay in the climate chamber, 
possibly making them aware of those temporal and qualitative changes in light. Significant correlations at 0.01 level were mostly found for the equatorial façade orientation and for the questionnaire item Q.5 regarding their light preference at desk level. There seems to be thus a seasonal influence of daylight availability on daylight sensitivity.

In winter, inverse correlations are found for illuminance at desk level with Q.5, indicating that participants would rather have the illumination level darker at the workplace in Eq. This could be related to an enhanced sensitivity of them for the large variation in light intensity during winter sessions for that window orientation, ranging on average from almost dim light (with a mean of $140 \mathrm{~lx}$ at $9 \mathrm{a} . \mathrm{m}$. and lower than that at $8 \mathrm{a.m}$., about $30 \mathrm{lux}$ ) to brighter conditions throughout the sessions (with an average peak of 1,254 lx, at 12:50 p.m., cf. Table 4). Also in Eq, CCT was found to be significantly correlated to Q.5 during winter. In Neq, CCT is strongly but inversely correlated to Q.7 that evaluates preference in the indoor environment as a whole and not specifically at desk level. Q.5 is suggested to be the questionnaire item more suitable to gauge such enhanced sensitivity in winter.

Summer correlations are stronger, though only significant at 0.05 level, for the quality of light (DWl and $\mathrm{a}_{\mathrm{cv}}$ ) in relation to preference of room illuminance (Q.7) in the nonequatorial room. DWl slightly follows the rising pattern of room illuminance and $\mathrm{a}_{\mathrm{cv}}$ drops from the start to the end of the summer sessions, thus the direct and inverse relationships to Q.7 were expected despite the very small variation in such variables during sessions. Also in summer, in Eq, satisfaction with daylight conditions in the room is directly correlated to room illuminance.

\section{Physiological Changes in Skin Temperature}

Figures 3, 4 show aggregated seasonal behavior of $\mathrm{T}_{\mathrm{sk}}$ for $\mathrm{Eq}$ and Neq configurations.

For all seasons compared, obtained correlations of $\mathrm{T}_{\text {sk }}$ to a linear trend line are weaker in the $\mathrm{Neq}$, relative to the $\mathrm{Eq}$ configuration. A possible explanation for that lies in the higher variation of lighting levels in Eq during the course of the sessions, which produces a stronger effect on $\mathrm{T}_{\text {sk. }}$. In addition, as noticed in Table 3, variations are more dramatic in terms of daylight exposure, intensity and quality during the winter sessions, whereas in the other seasons such variations are much less pronounced. Hence, correlations to $\mathrm{T}_{\text {sk }}$ are stronger both in Eq and Neq for that season (cf. Figures 3, 4).

The pattern of the obtained regression trend lines also shows higher slope coefficients for both Eq and Neq in winter, slightly lower slopes for spring and a nearly zero slope coefficient for summer, meaning that changes in skin temperatures are barely noticed over the hours of the summer sessions.

Thus, a marked dependency on daylight exposure for eliciting $\mathrm{T}_{\mathrm{sk}}$ changes and a seasonal impact on their development are observed, likely given as a function of the variability of light conditions during sessions.

Again, it must be reminded that the indoor environment was kept within a narrow range of thermal conditions, equivalent to a Class B thermal environment (PMV ranging between -0.5 and +0.5 ) and in some sessions even reaching Class A conditions (PMV range -0.2 to +0.2 , ISO 7730 ISO 7730,2005 ), so as to minimize confounding effects of thermal variations throughout the sessions.

Paired sample $t$-tests for both configurations with daylight are shown in Tables 5, 6.

The comparison between seasons for Eq shows that the pattern of $\mathrm{T}_{\mathrm{sk}}$ of the respondents group does not differ significantly between summer and winter with $t_{(326)}=0.53$ and $p=0.60$. For the other interseasonal comparisons, i.e., spring vs. summer and spring vs. winter, there are statistical differences between series, with $p \leq 0.01$.

For Neq, statistically significant differences are found at 0.01 level for all conditions, except for spring vs. summer. Despite the very similar values found for $\mathrm{T}_{\mathrm{sk}}$ between seasons as noticed in Table 3, such differences are statistically significant and changes in pattern are visible between seasons.

\section{DISCUSSION}

Results found for subjective responses in terms of light perception as well as physiological changes point to an unequivocal impact of the season of the year on these variables. Both experimental setup and analysis can be seen as attempts to fill the gaps identified by Aries et al. (2015) in their literature review, in the sense of providing well-documented scientific proof for the link between daylight and humans, though not specifically related to health but to non-visual effects of daylight exposure.

The issue of circadian disruption as represented here by a biological marker (skin temperature, $\mathrm{T}_{\mathrm{sk}}$ ) for the same sample of individuals in a comparison between static, electric light and dynamic light exposure was explored in another paper by the authors of this chapter (Tamura et al., 2021). There, it was shown that the course of $\mathrm{T}_{\text {sk }}$ is dependent on available daylight and that under electric light sources $\mathrm{T}_{\text {sk }}$ behaves according to an invariable pattern. As sessions took place during the morning, when daylight exposure stimulates the functioning of the circadian clock and elicits alertness in humans (Andersen et al., 2012), differences in behavior between dynamic light and static electric light in terms of $\mathrm{T}_{\mathrm{sk}}$ became evident, pointing to a positive influence of the daylight properties.

TABLE 5 | Paired sample $t$-test for $T_{\text {sk }}$ in equatorial configuration with season effect.

\begin{tabular}{lllll}
\hline Pair & \multicolumn{2}{c}{ Paired differences } & Sig. (2-tailed) \\
\cline { 1 - 2 } & Mean Std. deviation & Std. error mean & 95\% confidence interval of the differences & df
\end{tabular}

\begin{tabular}{|c|c|c|c|c|c|c|c|c|c|c|}
\hline No. & Var. 1 & Var. 2 & & & & Lower & Upper & & & \\
\hline 1 & Eq summer & Eq winter & 0.06 & 1.95 & 0.11 & -0.15 & 0.27 & 0.53 & 326 & 0.60 \\
\hline 2 & Eq spring & Eq summer & 0.29 & 1.93 & 0.10 & 0.08 & 0.49 & 2.75 & 343 & 0.01 \\
\hline 3 & Eq spring & Eq winter & 0.21 & 0.56 & 0.03 & 0.15 & 0.27 & 6.88 & 343 & 0.00 \\
\hline
\end{tabular}

TABLE 6 | Paired sample $t$-test for $T_{\text {sk }}$ in non-equatorial configuration with season effect.



\begin{tabular}{|c|c|c|c|c|c|c|c|c|c|c|}
\hline No. & Var. 1 & Var. 2 & & & & Lower & Upper & & & \\
\hline 1 & Neq summer & Neq winter & 0.35 & 0.69 & 0.04 & 0.28 & 0.42 & 9.44 & 348 & 0.00 \\
\hline 2 & Neq spring & Neq summer & 0.07 & 0.71 & 0.04 & 0.00 & 0.15 & 1.87 & 335 & 0.06 \\
\hline 3 & Neq spring & Neq winter & 0.28 & 0.90 & 0.05 & 0.19 & 0.37 & 5.89 & 358 & 0.00 \\
\hline
\end{tabular}


The seasonal effect observed in the present study in the interseasonal comparisons was not that significant in terms of $\mathrm{T}_{\text {sk }}$ disruption although patterns of $\mathrm{T}_{\text {sk }}$ for the three seasons in both solar orientations were visibly different (Figures 3, 4). The study, conducted under thermally controlled conditions in a state-of-the-art climate chamber for varying daylight exposure, corroborated existing knowledge that physiological changes linked to circadian rhythms are dependent on available daylight. The use of $\mathrm{T}_{\text {sk }}$ as a non-invasive and low-cost biological marker proved that such variable can be a fairly good indicator of how light exposure affects the human body (Tamura et al., 2021). Observed differences in the relationship between subjective responses and light exposure further corroborated findings concerning $\mathrm{T}_{\text {sk }}$ that also point to seasonal impacts on daylight perception. As pointed out in the introductory part of this chapter, both aspects are interrelated, light perception and circadian functions as evidence suggests that blind people without light perception are at a greater risk of circadian rhythm disorders (Hartley et al., 2018).

The fact that the winter sessions yielded higher and statistically significant Spearman rank-order correlations between light-related variables and subjective responses is here suggested to be related to the greater variability in daylight conditions during those sessions. Subjective responses according to a dim-bright voting scale for rising illuminance levels showed in a field study a logarithmic relationship between them, with light perception leveling off after a given illuminance level (Parpairi, 2004). In the present study, the large variability in exposure conditions in winter lied within the steep rise in perception to changes in light of the reported study and is deemed to have created more discernible responses in that season than in spring and summer, when light-related variables surpassed the threshold with diminishing returns in terms of perception and luminic comfort. This finding is important and may serve as an alert to urban densification schemes that largely affect daylight access (Lobaccaro and Frontini, 2014; López et al., 2016), as dwellers in densified cities are prone to become more sensitive to daylight changes. As luminic comfort is an important element of IEQ concerns, this issue rises in importance.

From 2020, with the onset of the COVID-19 pandemic, the various lockdown periods and the switch to home office and distant-learning activities made evident the various IEQ inadequacies of enclosed spaces, among them daylight access. As put forth by Bergefurt et al. (2021) in a recent cross-sectional study in the Netherlands with 393 employees working from home during the pandemic, discomfort from lighting in such environments can be due to conflicting lighting and asthetic requirements regarding quality and quantity of daylight and artificial light in home workplaces. Recognizing that lighting conditions are in a great deal relevant to human health, mental state and productivity, our study intends to contribute even if in a minor way to the understanding of such relationships.

\section{CONCLUSIONS}

In summary, our findings suggest that mainly when users of indoor spaces have to struggle with limited light requirements, they become more sensitive to minor changes in available light and the circadian factor is more easily affected and activated. This conforms to daylight requirements in winter, particularly in high-latitude locations, for curbing the risk of SAD or Winter Depression. In many countries health authorities are aware of the benefits obtained from phototherapy, light therapy or simply from longer exposures to daylight.

In other regions of the world which remain unaffected by relevant changes in day length and solar intensity as in tropical areas, the lack of access to daylight, which can severely affect circadian functions, can be primarily linked to poor building and urban design, that prevents dwellers, office users and occupants of indoor built spaces in general to receive an adequate amount of daylight on a daily basis. In developing countries in hot climates, urban agglomerations with densely built spaces, associated or not to deliberate urban compaction schemes or just resulting from informal settlements are part of the problem. Another complication is related to life style, with the gradual move of stores from open streets to safer, air-conditioned, enclosed spaces such as shopping malls with restricted access to daylight. Another trend is the widespread construction of light-weight buildings with excessive glazing, typically treated with tainted or highreflective glass which greatly reduces the amount of available daylight indoors. Frequently office and mall employees spend most of the day under artificial light and are at risk having circadian rhythm disorders. Consequences are not only healthrelated but can also affect their productivity.

Limitations of the study include the sample size and the lack of other monitored physiological parameters. Crosssectional studies with larger samples in real environments could provide more evidence of the relationships found in our study. As for assessing physiological markers, our findings suggest that the skin temperature can be a good noninvasive and low-cost approach for identifying relevant lightwellbeing-health relationships. Future studies are encouraged to evaluate the feasibility of using other tools and measures for such assessments.

\section{DATA AVAILABILITY STATEMENT}

The original contributions presented in the study are included in the article/supplementary materials, further inquiries can be directed to the corresponding author.

\section{ETHICS STATEMENT}

The studies involving human participants were reviewed and approved by Ethics Committee of the Karlsruhe Institute of Technology. The patients/participants provided their written informed consent to participate in this study.

\section{AUTHOR CONTRIBUTIONS}

The author confirms being the sole contributor of this work and has approved it for publication. 


\section{ACKNOWLEDGMENTS}

I would like to acknowledge the Brazilian Research Funding Agency CAPES, the European Union 7th Framework Program (FP7/2007-2013) Grant Agreement

\section{REFERENCES}

Andersen, M., Mardaljevic, J., and Lockley, S. W. (2012). A framework for predicting the non-visual effects of daylight-part I: photobiology-based model. Light. Res. Technol. 44, 37-53. doi: 10.1177/1477153511435961

Aries, M. B., Aarts, M. P., and van Hoof, J. (2015). Daylight and health: a review of the evidence and consequences for the built environment. Light. Res. Technol. 47, 6-27. doi: 10.1177/1477153513509258

Bergefurt, A. G. M., Weijs-Perrée, M., Appel-Meulenbroek, R., and Arentze, T. A. (2021). "The influence of employees' workspace satisfaction on mental health while working from home during the COVID-19 pandemic," in Healthy buildings 2021 - Europe (Oslo), 1-9.

Betti, G., Tartarini, F., Schiavon, S., and Nguyen, C. (2021). CBE Clima Tool. Version 0.4.6. Center for the Built Environment, University of California Berkeley. Available online at: https://clima.cbe.berkeley.edu (accessed December 2021)

Boudreau, P., Yeh, W. H., Dumont, G. A., and Boivin, D. B. (2012). A circadian rhythm in heart rate variability contributes to the increased cardiac sympathovagal response to awakening in the morning. Chronobiol. Int. 29, 757-768. doi: 10.3109/07420528.2012.674592

Brainard, G. C., Hanifin, J. P., Greeson, J. M., Byrne, B., Glickman, G., Gerner, E., et al. (2001). Action spectrum for melatonin regulation in humans: evidence for a novel circadian photoreceptor. J. Neurosci. 21, 6405-6412. doi: 10.1523/JNEUROSCI.21-16-06405.2001

Buhr, E. D., Yoo, S. H., and Takahashi, J. S. (2010). Temperature as a universal resetting cue for mammalian circadian oscillators. Science 330, 379-385. doi: $10.1126 /$ science. 1195262

Chellappa, S. L., Steiner, R., Blattner, P., Oelhafen, P., Götz, T., and Cajochen, C. (2011). Non-visual effects of light on melatonin, alertness and cognitive performance: can blue-enriched light keep us alert?. PLoS ONE 6, e16429. doi: 10.1371/journal.pone.0016429

Chinazzo, G., Wienold, J., and Andersen, M. (2019). Daylight affects human thermal perception. Sci. .orts 9, 1-15. doi: 10.1038/ s41598-019-48963-y

Dai, Q., Cai, W., Shi, W., Hao, L., and Wei, M. (2017). A proposed lighting-design space: circadian effect versus visual illuminance. Build. Environ. 122, 287-293. doi: 10.1016/j.buildenv.2017.06.025

Flynn-Evans, E. E., Tabandeh, H., Skene, D. J., and Lockley, S. W. (2014). Circadian rhythm disorders and melatonin production in 127 blind women with and without light perception. J. Biol. Rhythms 29, 215-224. doi: $10.1177 / 0748730414536852$

Gall, D., Vandahl, C., and Bieske, K. (2004). Die Ermittlung von Licht- und Farbfeldgrößen zur Bestimmung der spektralen Wirkung des Lichtes. in: Proceedings LICHT, Dortmund (2004)

Hartley, S., Dauvilliers, Y., and Quera-Salva, M. A. (2018). Circadian rhythm disturbances in the blind. Curr. Neurol Neurosci. Rep. 18, 1-8. doi: 10.1007/s11910-018-0876-9

ISO 7726. (2001). Ergonomics of the Thermal Environment. Instruments for Measuring Physical Quantities. Geneva: International Organization for Standardization (ISO).

ISO 7730. (2005). Moderate Thermal Environment. Determination of the PMV and PPD Indices and Specification of the Conditions for Thermal Comfort. Geneva: International Organization for Standardization.

ISO 9886. (2004). Ergonomics. Evaluation of Thermal Strain by Physiological Measurements. Geneva: International Organization for Standardization.

ISO 9920. (2007). Ergonomics of the Thermal Environment. Estimation of Thermal Insulation and Water Vapour Resistance of a Clothing Ensemble. Geneva: International Organization for Standardization.

Ko, W. H., Schiavon, S., Zhang, H., Graham, L. T., Brager, G., Mauss, I., et al. (2020). The impact of a view from a window on thermal
No. PIRG08-GA-2010-277061, the Fachgebiet Bauphysik and Technischer Ausbau/Karlsruher Institut für Technologie (fbta/KIT), and in special Marcel Schweiker and Andreas Wagner. Special thanks to my former Ph.D. student, Cintia Tamura.

comfort, emotion, and cognitive performance. Build. Environ. 175, e106779. doi: 10.1016/j.buildenv.2020.106779

Kottek, M., Grieser, J., Beck, C., Rudolf, B., and Rubel, F. (2006). World map of the Köppen-Geiger climate classification updated. Meteorol. Zeitschrift 15, 259-263. doi: 10.1127/0941-2948/2006/0130

Krüger, E. L., Tamura, C., and Trento, T. W. (2018). Identifying relationships between daylight variables and human preferences in a climate chamber. Sci. Total Environ. 642, 1292-1302. doi: 10.1016/ j.scitotenv.2018.06.164

Kudielka, B. M., and Kirschbaum, C. (2003). Awakening cortisol responses are influenced by health status and awakening time but not by menstrual cycle phase. Psychoneuroendocrinology 28, 35-47. doi: 10.1016/S0306-4530(02)00008-2

Lam, C. K. C., Krüger, E. L., Callejas, I. J. A., and Wagner, A. (2021). "Long and short-term acclimatization effects on outdoor thermal perception versus UTCI," in: Applications of the Universal Thermal Climate Index UTCI in Biometeorology, Vol 4, eds E. L. Krüger Springer, Cham.

Lobaccaro, G., and Frontini, F. (2014). Solar energy in urban environment: how urban densification affects existing buildings. Energy Proc. 48, 1559-1569. doi: 10.1016/j.egypro.2014.02.176

López, C. S. P., Sala, M., Tagliabue, L. C., Frontini, F., and Bouziri, S. (2016). Solar radiation and daylighting assessment using the Sky-View Factor (SVF) analysis as method to evaluate urban planning densification policies impacts. Energy Proc. 91, 989-996. doi: 10.1016/j.egypro.2016. 06.266

Mead, M. N. (2008). Benefits of sunlight: a bright spot for human health. Environ. Health Persp. 116, A160-A167. doi: 10.1289/ ehp.116-a160

Parpairi, K. (2004). "Daylight perception," in Environmental Diversity in Architecture, 1st Edn, eds M. A. Steane and K. Steemers (Routledge), 112-252. doi: $10.4324 / 9780203561270$

Qian, J., Morris, C. J., Caputo, R., Garaulet, M., and Scheer, F. A. (2019). Ghrelin is impacted by the endogenous circadian system and by circadian misalignment in humans. Int. J. Obes. 43, 1644-1649. doi: 10.1038/ s41366-018-0208-9

Sharma, A., Tiwari, S., and Singaravel, M. (2016). Circadian rhythm disruption: health consequences. Biol. Rhythm Res. 47, 191-213. doi: 10.1080/09291016.2015.1103942

Smolensky, M. H., Hermida, R. C., Castriotta, R. J., and Portaluppi, F. (2007). Role of sleep-wake cycle on blood pressure circadian rhythms and hypertension. Sleep Med. 8, 668-680. doi: 10.1016/ j.sleep.2006.11.011

Stefani, O., Freyburger, M., Veitz, S., Basishvili, T., Meyer, M., Weibel, J., et al. (2020). Changing color and intensity of LED lighting across the day impacts on human circadian physiology, sleep, visual comfort and cognitive performance. bioRxiv [Preprint]. doi: 10.1101/2020.04.21.771832

Tamura, C. A., Krüger, E. L., Wagner, A., and Strauhs, F. R. (2021). Analyzing potential correlations between light exposure and skin temperature in a climate chamber. Build. Environ. 205, 108242. doi: 10.1016/ j.buildenv.2021.108242

Thapan, K., Arendt, J., and Skene, D. J. (2001). An action spectrum for melatonin suppression: evidence for a novel non-rod, non-cone photoreceptor system in humans. J. Physiol. 535, 261-267. doi: 10.1111/ j.1469-7793.2001.t01-1-00261.x

Vandahl, C., Moosmann, C., and Funke, C. (2016). "Uniform assessment of lighting situations with the LiTG Questionnaire - first experiences," in Conference Proceedings LICHT. Karlsruhe (2016).

Wagner, A., O'Brien, W., and Dong, B. (2018). Exploring Occupant Behavior in Buildings - Methods and Challenges. Cham: Springer International Publishing. 
Walker, W. H., Walton, J. C., DeVries, A. C., and Nelson, R. J. (2020). Circadian rhythm disruption and mental health. Transl. Psychiatry 10, 1-13. doi: 10.1038/s41398-020-0694-0

Conflict of Interest: The author declares that the research was conducted in the absence of any commercial or financial relationships that could be construed as a potential conflict of interest.

Publisher's Note: All claims expressed in this article are solely those of the authors and do not necessarily represent those of their affiliated organizations, or those of the publisher, the editors and the reviewers. Any product that may be evaluated in this article, or claim that may be made by its manufacturer, is not guaranteed or endorsed by the publisher.

Copyright $\odot 2022$ Krüger. This is an open-access article distributed under the terms of the Creative Commons Attribution License (CC BY). The use, distribution or reproduction in other forums is permitted, provided the original author(s) and the copyright owner(s) are credited and that the original publication in this journal is cited, in accordance with accepted academic practice. No use, distribution or reproduction is permitted which does not comply with these terms. 